\title{
AMERICAN MATHEMATICAL SOCIETY PUBLICATIONS
}

(Continued from inside front cover)

Colloquium Series-(Continued)

12.* S. Lefschetz, Topology, 1930, x, 410 pp.

13.* R. L. Moore, Foundations of Point Set Theory, 1932, viii, 486 pp.

14. J. F. Ritt, Differential Equations from the Algebraic Standpoint, 1932, x, 172 pp.

15. M. H. Stone, Linear Transformations in Hilbert Space and Their Applications to Analysis, 1932, viii, 622 pp.; reprinted, 1946, viii, $622 \mathrm{pp}$.

16. G. A. Bliss, Algebraic Functions, 1933, x, 218 pp.

17. J. H. M. Wedderburn, Lectures on Matrices, 1934, viii, 200 pp.; reprinted, 1944, x, 205 pp.

18. M. Morse, The Calculus of Variations in the Large, 1934, x, $368 \mathrm{pp}$.

19. R. E. A. C. Paley and N. Wiener, Fourier Transforms in the Complex Domain, 1934, viii, 184 pp.+portrait plate.

20. J. L. Walsh, Interpolation and Approximation by Rational Functions in the Complex Domain, 1935, x, 382 pp.

21. J. M. Thomas, Differential Systems, 1937, x, 118 pp.

22. C. N. Moore, Summable Series and Convergence Factors, 1938, vi, $105 \mathrm{pp}$.

23. G. Szegö, Orthogonal Polynomials, 1939, x, 401 pp.

24. A. A. Albert, Structure of Algebras, 1939, xii, 210 pp.

25.* G. Birkhoff, Lattice Theory, 1940, vi, 155 pp.

26. N. Levinson, Gap and Density Theorems, 1940, viii, 246 pp. $\quad 4.00$

27. S. Lefschetz, Algebraic Topology, 1942, vi, 389 pp. 6.00

28. G. T. Whyburn, Analytic Topology, 1942, x, 278 pp. 4.75

29. A. Weil, Foundations of Algebraic Geometry, 1946, xx, 288 pp. $\quad 5.50$

\section{Mathematical Surveys}

1. J. A. Shohat and J. D. Tamarkin, The Problem of Moments, 1943, xiv, $140 \mathrm{pp}$.

2. N. Jacobson, The Theory of Rings, $1943, \mathrm{vi}, 150 \mathrm{pp}$. 2.25

* Out of print.

Entered as second class matter April 24, 1926, at the post. office at Menasha, Wis., under the act of August 24, 1912. Acceptance for maniing at the special rate of postage provided for in the act ot February 28, 1925, embodied in paragraph 4, section 538, P. l. and R., authorized May 9, 1935. 


\section{AMERICAN MATHEMATICAL SOCIETY DIRECTORY}

\section{General Office: Room 305, Low Memorial Library, 531 West 116th Street, New York}

27, N. Y.

This address should be used for all mail which concerns membership, subscriptions, changes of address, etc. Mail for Librarian and Treasurer should be sent to General Office.

Editorial Office, Mathematical Reviews: Brown University, Providence 12, R. IDr. R. P. Boas, Executive Editor.

This address should not be used for subscriptions and payments, etc. Correspondence about these matters should go to the Society's General Office.

\section{Officers and Editors:}

President: Professor T. H. Hildebrandt, University of Michigan, Ann Arbor, Mich.

Secretary: Professor J. R. Kline, American Mathematical Society, University of Pennsylvania, Philadelphia 4, Pa.

Associate Secretaries:

Professor R. H. Bruck, University of Wisconsin, Madison 6, Wis.

Professor T. R. Hollcroft, Wells College, Aurora, N. Y.

Professor G. B. Price, University of Kansas, Lawrence, Kan.

Professor A. C. Schaeffer, Stanford University, Stanford University, Calif.

Treasurer: Professor B. P. Gill, College of the City of New York, New York 31, N.Y.

Librarian: Professor Arnold Dresden, Swarthmore College, Swarthmore, Pa.

Managing Editor of the Bulletin: Professor Saunders MacLane, 246 Widener, Harvard University, Cambridge 38, Mass.

Managing Editor of the Transactions: Professor A. A. Albert, University of Chicago, Chicago 37, Ill.

Editors of Mathematical Reviews:

Professor O. E. Neugebauer, Brown University, Providence 12, R.I.

Professor M. H. Stone, University of Chicago, Chicago 37, III.

Professor Oswald Veblen, Institute for Advanced Study, Princeton, N.J.

Chairman, Colloquium Editorial Committee: Professor G. T. Whyburn, University of Virginia, Charlottesville, Va.

Chairman, Mathematical Surveys Editorial Committee: Professor Nelson Dunford, Yale University, New Haven, Conn.

Editors of American Journal of Mathematics:

Professor Richard Brauer, University of Toronto, Toronto, Ont., Canada.

Professor L. M. Graves, University of Chicago, Chicago 37, Ill.

Professor F. D. Murnaghan, Johns Hopkins University, Baltimore 18, Md.

Professor Hassler Whitney, Harvard University, Cambridge 38, Mass.

Professor Aurel Wintner, Johns Hopkins University, Baltimore 18, Md.

A list of chairmen of departments of mathematics at various colleges and universities may be obtained from the Secretary, American Mathematical Society, University of Pennsylvania, Philadelphia $4, \mathrm{~Pa}$. 